\title{
(6) OPEN ACCESS \\ More fatal all-terrain vehicle crashes occur on the roadway than off: increased risk-taking characterises roadway fatalities
}

\author{
Gerene M Denning, ${ }^{1}$ Karisa K Harland ${ }^{1}{ }^{1} 2$ David G Ellis, ${ }^{1}$ Charles A Jennissen ${ }^{1}$
}

${ }^{1}$ Department of Emergency Medicine, University of lowa, Roy $\mathrm{J}$ and Lucille $\mathrm{A}$ Carver College of Medicine, lowa City, lowa, USA

${ }^{2}$ Injury Prevention Research Center, College of Public Health, University of lowa, lowa City, lowa, USA

\section{Correspondence to} Dr Gerene Denning, Department of Emergency Medicine, 1008 Roy Carver Pavilion, University of lowa, Hospitals and Clinics,

200 Hawkins Drive, lowa City, IA 52242, USA:

gerene-denning@uiowa.edu

Received 3 July 2012 Revised 5 November 2012 Accepted 25 November 2012 Published Online First 20 December 2012

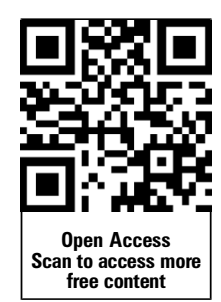

\begin{abstract}
Background All-terrain vehicles (ATVs) have steadily increased in popularity, size and speed, characteristics that likely contribute to the alarming rise in ATV-related fatalities. One potentially high-risk activity is riding on the road.
\end{abstract}

Objectives To compare fatal ATV crashes that occur on the roadway and off, to more fully understand factors that contribute to fatalities at each location.

Methods Fatality data from the US Consumer Product Safety Commission (CPSC) were used for descriptive and comparative analyses. Multivariate logistic regression analysis was performed to determine relative risk.

Results Over $60 \%$ of all fatalities (1985-2009) resulted from roadway crashes. After 1998, roadway fatalities increased at over twice the rate of off-road fatalities. Roadway crashes were more likely than off-road crashes to involve multiple fatalities, carrying passengers, alcohol use, collisions and head injuries. Roadway victims were less likely to be helmeted than off-road victims.

Passengers and operators with passengers were also less likely to be helmeted than operators riding alone. Helmeted victims were half as likely to suffer a head injury.

Conclusions Fatal roadway crashes were more likely than off-road crashes to involve risk-taking behaviours (eg, carrying passengers) that could exacerbate the inherent difficulty of operating ATVs on roadway surfaces. Higher crash forces from greater speed, and lower use of protective equipment, may also have contributed to higher roadway mortality rates. Eliminating non-essential ATV road use may be an effective way to reduce ATVrelated fatalities. This will likely require a substantial investment in rider education and better enforcement of ATV road use restriction laws.

\section{INTRODUCTION}

The US Consumer Product Safety Commission (CPSC) has monitored all-terrain vehicle (ATV)related fatalities for the past three decades. ${ }^{1}$ Their reports indicate a significant increase in fatalities over time. The highest level observed was 833 fatalities in 2006. ${ }^{1}$

This increase in fatalities likely reflects the vehicle's increasing popularity, and the production and marketing of larger, faster ATVs. Current models can weigh over 800 pounds and achieve speeds in excess of $80 \mathrm{mph}^{2}$ In 2008, the number of ATVs in the USA was estimated to be 10.2 million, greater than triple the number a decade earlier. ${ }^{3}$ ATVs are used for agriculture, industry, law enforcement and other work-related purposes; however, the majority of ATV use is recreational. ${ }^{45}$
A number of risk factors for ATV-related fatalities and injuries have been identified. They include being male or under the age of 16, operating age-inappropriate adult-sized vehicles, lack of training and experience, alcohol and drug use, lack of personal protective equipment especially helmets, and carrying passengers on single-person vehicles. ${ }^{6-10}$ Another independent risk factor for ATV crashes is riding on the road. ${ }^{9} 1112$ Elements of ATV design, including a high centre of gravity and knobby, low-pressure tyres, likely increase the risk of operators losing control of the vehicle on roadway surfaces, particularly at roadway speeds, and/or when making right angle traffic turns. ${ }^{10} 13$

Despite the fact that most states restrict ATV road use to work-related purposes, exposure studies indicate that riders of all ages are operating these vehicles on the roads. ${ }^{14}$ A survey of over 3000 lowa students (primarily 11-15 years of age) found that $85 \%$ rode an ATV at least a few times a year, with $81 \%$ of those reporting having ridden on a public road (Charles Jennissen, manuscript in preparation).

In a West Virginia study of ATV-related fatalities, the authors found that $60 \%$ of fatal crashes occurred on the road. ${ }^{15}$ In this study, we expand upon these findings to identify location-specific characteristics for fatal ATV crashes nationwide.

\section{METHODS}

\section{Data source}

This was a retrospective study of ATV-related fatalities from 1985 through 2009 using CPSC data from all 50 states, Washington, DC, and Puerto Rico. Data were obtained using the CPSC online request form. ${ }^{16}$ Because the study involved secondary analysis of deidentified data, it was deemed Institutional Review Board (IRB) exempt.

Crash location was coded using the CPSC variable 'road'. Roadway crash codes were 01 (public roads), 02 (private roads), and 05 (road, nothing else known). The off-road crash code was 09 (not a road). Unknown was 00. To determine the total number of documented injuries among the fatality victims, we combined three fields-body part, injury type and the cause of fatality. A 'Yes/No/ Unknown' coded variable was then created for head, neck, spine and torso injuries. Because the cause of fatality narrative was often non-specific, like 'multiple blunt force injuries', and fatal injuries could not always be identified, all injuries recorded for fatality victims were included in analysis. 


\section{Data analysis}

Only the years for which recorded fatalities were indicated by the CPSC to be complete (1985-2006) were used to calculate changes in the number of fatalities over time. Data from all years were used for descriptive, comparative and multivariate analyses. Descriptive analyses were performed using Microsoft Excel 2010. All other statistical analyses were performed using SAS software, V.9.2 of the SAS System for Microsoft (SAS Institute Inc, Cary, North Carolina, USA). Continuous variables (eg, age) were compared using the non-parametric MannWhitney test, as the distributions were found to be non-Gaussian. Comparisons of proportions were done using the $\chi^{2}$ test. Multivariate logistic regression analysis was used to calculate unadjusted and adjusted ORs and 95\% CI for categorical variables, after controlling for significant covariates. Victims with missing data for one or more of the variables were not included in multivariate analysis.

\section{RESULTS}

\section{Fatal crashes}

There were a total of 10272 ATV-related fatalities in the CPSC database for 1985-2009, with 9615 documented for crash location, that is, on or off the road. Among those documented, $5978(62 \%)$ resulted from roadway crashes. Both roadway and off-road fatalities increased over time (figure 1a). However, since 1998, the rate of increase in roadway fatalities was over twice that of off-road fatalities. In addition, table 1 indicates that the proportion of crashes that resulted in multiple fatalities was over three times higher on the roadway than off.

\section{Rider characteristics}

A significantly lower proportion of victims under the age of 16 were observed in roadway crashes, as compared with off-road crashes (table 2), and the proportion of young adults 1625 years of age was particularly high on the roads (figure $1 \mathrm{~b}$ ). Operators carrying passengers, and passengers themselves, were also a higher proportion of victims on the roadway than off.

Overall helmet use was lower among roadway crash victims than among off-road victims. More specifically, helmet use was lower among roadway victims who were adults, operators riding alone, or passengers relative to their off-road peers.

More fatalities involved alcohol on the roadway than off, and there were a higher proportion of roadway victims positive for illicit drugs. Additionally, $42 \%$ of all victims in crashes involving alcohol were unhelmeted, as compared with $24 \%$ of victims when alcohol was not involved, $\mathrm{p}<0.0001$.

\section{Vehicle and crash characteristics}

Figure $2 \mathrm{a}$ illustrates how the engine size of vehicles involved in fatal crashes has increased over time. ATV-related fatalities involving vehicles with engine sizes over $350 \mathrm{cc}$ were first reported in 1999; and from 2004 through 2009, vehicles with engine sizes $>625 \mathrm{cc}$ have accounted for $12 \%$ of all fatal crashes. In terms of crash mechanism, a much higher proportion of ATV fatalities from roadway crashes involved a collision with another vehicle as compared with off-road crashes (table 2). By contrast, nearly three out of four off-road fatalities resulted from a non-collision event (ie, rollover).

\section{Injury characteristics}

Consistent with the increase in vehicle size, there was an approximate 3.5 -fold increase in fatality from compression asphyxia over time (figure $2 \mathrm{~b}$ ). Roadway crashes had a higher proportion of head and torso injuries, and a lower proportion of neck and spinal cord injuries relative to off-road crashes. However, only the difference in head injuries reached statistical significance (table 2).

\section{Relative risk based on crash location}

After controlling for covariates, persons under 16 years of age were $26 \%$ less likely to be victims of roadway crashes than of off-road crashes (table 3 ). Roadway crash victims were 19\% more likely to be operators carrying passengers, and 48\% more likely to be passengers relative to off-road victims. Additionally, roadway crash victims were $44 \%$ less likely to be helmeted than off-road victims, and $77 \%$ more likely to be in crashes involving alcohol. Fatalities involving a collision with another vehicle were over 11 times more likely to occur on than off the a

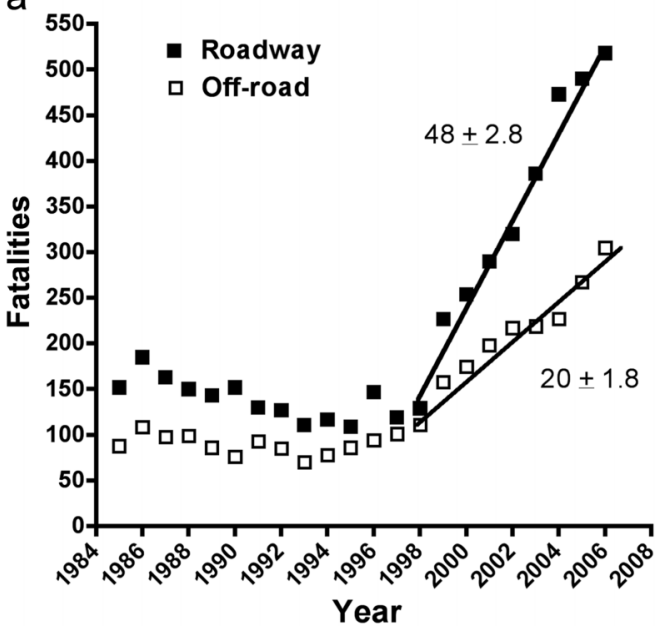

b

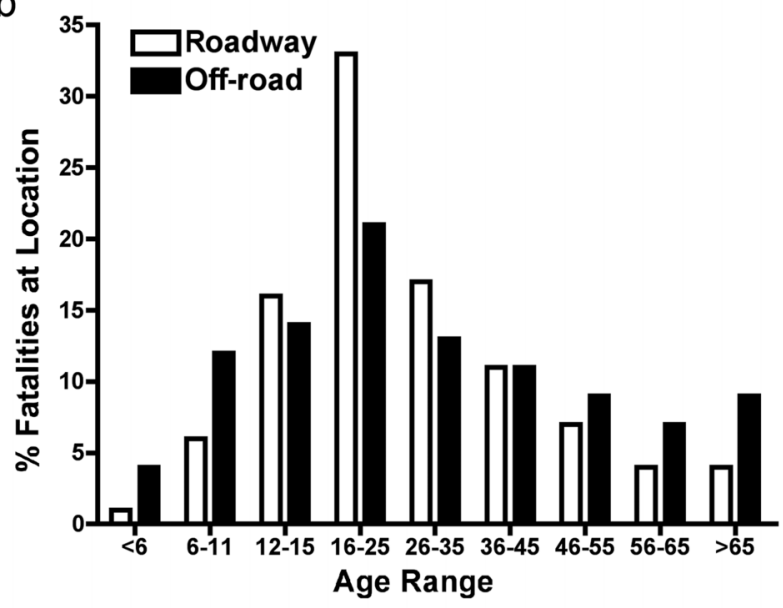

Figure 1 (a) CPSC data from 1985-2006 were used to plot the increase in fatalities over time. The rate of increase in roadway and off-road fatalities from 1998 to 2006 was then determined using linear regression analysis. The roadway rate was more than twice the off-road rate, $p<0.0001$. (b) CPSC data from 1985 to 2009 were used to determine the percentage of fatalities for the indicated age ranges on the roadway and off. 
Table 1 Comparison of the proportion and odds of crashes with multiple fatalities occurring on versus off the road from 1985 to 2009 ( $\mathrm{n}=5788$ crashes)

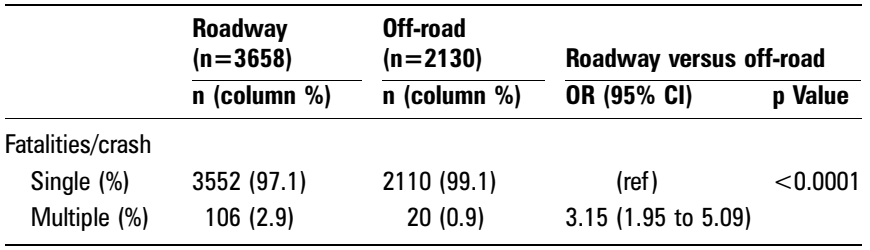

road, and collisions with other objects were nearly four times more likely to occur.

\section{Determinants of helmet use and head injury}

Overall, victims under 16 years of age were $76 \%$ more likely to be helmeted than were adults (table 4). However, only one quarter of youth victims were helmeted, at best. Both, operators carrying passengers and passengers themselves, were less likely to be helmeted than operators riding alone regardless of crash location. Victims from all crashes involving alcohol were $45 \%$ less likely to be helmeted than victims of crashes that did not. Similarly, fatality victims that were taking prescription medications had lower helmet use.

Head injuries were $28 \%$ more likely to occur among youth under 16 years of age than among adults (table 4). Additionally, for all fatal crashes, head injuries were $41 \%$ more likely to occur among passengers than among operators, $16 \%$ more likely to occur when alcohol was involved, and $45 \%$ more likely when the crashes were on the roadway than off. Helmeted victims were $46 \%$ less likely, overall, to suffer a head injury as compared with victims without helmets. However, helmeted victims of fatal roadway crashes were $33 \%$ more likely to suffer a head injury than helmeted off-road victims.

\section{DISCUSSION}

\section{Fatal on-road crashes}

Our study demonstrates that riding ATVs on the road is highly dangerous. Whereas previous studies, including ours, showed that around one-third of recorded injuries occurred on the roadway, ${ }_{1}^{11} 17$ we found that the proportion of roadway fatalities was almost twice that high (62\%). This percentage was similar to that found in a previous study for the state of West Virginia (60\%), but that study did not compare rider demographics and other characteristics of roadway versus off-road crashes. ${ }^{15}$ Of particular concern was our observation that fatal roadway crashes increased at more than twice the rate of off-road crashes. We hypothesise that this difference in fatality rate may reflect a rising use of ATVs on the roads, that is, more exposure, and that more road use reflects the rising popularity of faster, more powerful ATVs.

\section{Vehicle characteristics}

A General Accounting Office report estimated that there were over 10 million ATVs in the USA by 2008, with annual sales that year of 689000 vehicles..$^{10}$ A Canadian study demonstrated an increase in the sales of larger ATVs starting in the late $1990 \mathrm{~s}^{18}$ and this trend has continued, as evidenced by the models currently available at US dealerships. Consistent with these findings, our study showed an increasing proportion of vehicles with larger engine sizes in fatal crashes over time. Larger, faster vehicles may be contributing to rising ATV road use, as owners may be inclined to take to the road to exploit their vehicle's power and speed, or to use the vehicle as a source of transportation.
Table 2 Rider, crash and injury characteristics for ATV fatalities that occurred on versus off the road, CPSC, 1985-2009, ( $n=9615$ fatalities)

\begin{tabular}{|c|c|c|c|}
\hline & $\begin{array}{l}\begin{array}{l}\text { Roadway } \\
(\mathrm{n}=5978)^{*}\end{array} \\
\mathrm{n} \text { (column \%) }\end{array}$ & $\begin{array}{l}\begin{array}{l}\text { Off-road } \\
(\mathrm{n}=3637)^{*}\end{array} \\
\mathrm{n} \text { (column \%) }\end{array}$ & p Value \\
\hline \multicolumn{4}{|l|}{ Demographics } \\
\hline \multicolumn{4}{|l|}{ Sex } \\
\hline Male (\%) & $4596(89)$ & $2649(88)$ & 0.35 \\
\hline Female (\%) & $574(11)$ & $354(12)$ & \\
\hline \multicolumn{4}{|l|}{ Age } \\
\hline$<16(\%)$ & 1409 (24) & $1070(29)$ & $<0.0001$ \\
\hline$\geq 16(\%)$ & $4568(76)$ & $2567(71)$ & \\
\hline \multicolumn{4}{|l|}{ Seating position } \\
\hline Operator alone (\%) & $3345(69)$ & $2109(75)$ & $<0.0001$ \\
\hline Operator w/passenger (\%) & $799(16)$ & $364(13)$ & \\
\hline Passenger (\%) & $721(15)$ & $336(12)$ & \\
\hline \multicolumn{4}{|l|}{ Helmet use } \\
\hline \multicolumn{4}{|l|}{ All riders } \\
\hline Yes (\%) & $650(16)$ & $559(24)$ & $<0.0001$ \\
\hline No (\%) & $3488(84)$ & $1736(76)$ & \\
\hline \multicolumn{4}{|l|}{$<16$ years old } \\
\hline Yes (\%) & $249(25)$ & $198(27)$ & 0.30 \\
\hline No (\%) & $754(75)$ & $534(73)$ & \\
\hline \multicolumn{4}{|l|}{$\geq 16$ years old } \\
\hline Yes (\%) & $401(13)$ & $361(23)$ & $<0.0001$ \\
\hline No (\%) & 2734 (87) & $1202(77)$ & \\
\hline \multicolumn{4}{|l|}{ Operator alone } \\
\hline Yes (\%) & $507(18)$ & $474(28)$ & $<0.0001$ \\
\hline No (\%) & $2328(82)$ & $1229(72)$ & \\
\hline \multicolumn{4}{|l|}{ Operator w/passenger } \\
\hline Yes (\%) & $74(11)$ & $37(12)$ & 0.5302 \\
\hline No (\%) & $629(89)$ & $275(88)$ & \\
\hline \multicolumn{4}{|l|}{ Passenger } \\
\hline Yes (\%) & 55 (11) & $34(16)$ & $<0.05$ \\
\hline No (\%) & $453(89)$ & $174(84)$ & \\
\hline \multicolumn{4}{|l|}{ Alcohol and drugs } \\
\hline \multicolumn{4}{|l|}{ Alcohol } \\
\hline Yes (\%) & $1520(45)$ & $581(30)$ & $<0.0001$ \\
\hline No (\%) & $1850(55)$ & $1388(70)$ & \\
\hline \multicolumn{4}{|l|}{ Drugs } \\
\hline Yes-medication (\%) & $47(2.1)$ & $45(3.1)$ & 0.087 \\
\hline Yes-illicit (\%) & $215(9.5)$ & $83(5.7)$ & $<0.0001$ \\
\hline No (\%) & 1998 (88.4) & $1335(91.2)$ & \\
\hline \multicolumn{4}{|l|}{ Crash characteristics } \\
\hline \multicolumn{4}{|l|}{ Mechanism of crash } \\
\hline ATV-vehicle collision (\%) & 1671 (29) & $203(5.7)$ & $<0.0001$ \\
\hline ATV-other collision (\%) & $2168(37)$ & $779(22.5)$ & \\
\hline Non-collision & $1959(34)$ & $2482(71.8)$ & \\
\hline \multicolumn{4}{|l|}{ Injury (\%) } \\
\hline \multicolumn{4}{|l|}{ Head } \\
\hline Yes (\%) & $3741(66)$ & $1770(50)$ & $<0.0001$ \\
\hline No (\%) & $1959(34)$ & $1751(50)$ & \\
\hline \multicolumn{4}{|l|}{ Neck } \\
\hline Yes (\%) & $478(8.4)$ & $333(9.5)$ & 0.08 \\
\hline No (\%) & $5222(91.6)$ & $3188(90.5)$ & \\
\hline Spine & & & \\
\hline Yes (\%) & $181(3.2)$ & $130(3.7)$ & 0.18 \\
\hline No (\%) & $5519(96.8)$ & $3391(96.3)$ & \\
\hline Torso & & & \\
\hline Yes (\%) & $1610(28)$ & $944(26)$ & 0.13 \\
\hline No $(\%)$ & $4090(72)$ & $2577(73)$ & \\
\hline
\end{tabular}

${ }^{*}$ Column totals may not equal overall totals due to missing values.

ATV, All-terrain vehicle.

ATVs have a high centre of gravity and a narrow wheelbase that are designed for off-road riding. However, these features require that the vehicle takes wider turns than are found in 

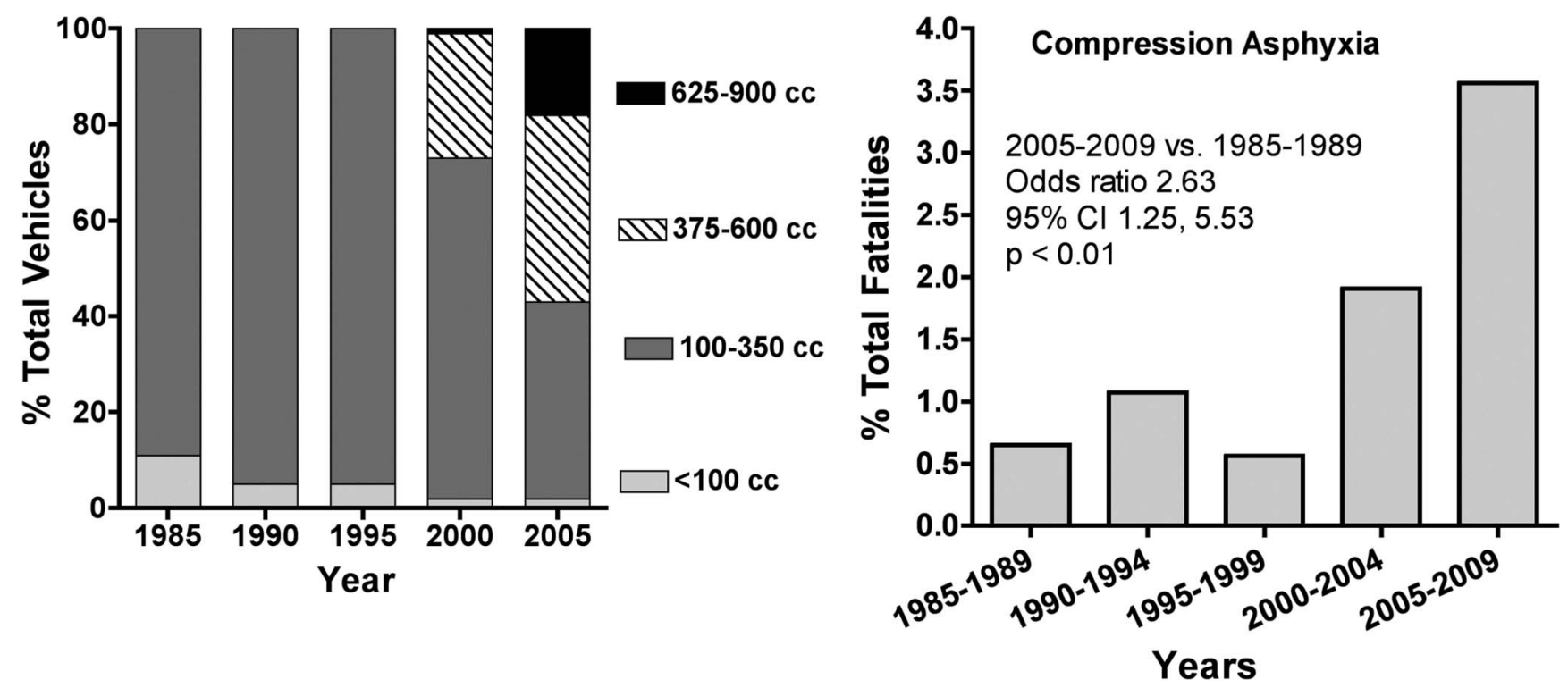

Figure 2 (a) The percentage of vehicles with engine sizes within the indicated size range was determined for the indicated year. Data show an increase in the proportion of vehicles with larger engine sizes that were involved in fatal crashes over time. (b) The percentage of fatalities due to compression asphyxia was calculated for the indicated time periods.

standard road design. In addition, low-pressure ATV tyres designed to handle off-road terrains can improperly interact with road surfaces. These vehicle characteristics become more problematic at higher speeds. ${ }^{10} 13$ The increasing vehicle weight of larger ATVs may also increase the risk of fatality and injury for victims struck or pinned by the vehicle. Our data showed

Table 3 Unadjusted and adjusted odds of ATV fatalities comparing on versus off the road; CPSC, 1985-2009, ( $n=9615$ fatalities)

\begin{tabular}{|c|c|c|}
\hline & \multicolumn{2}{|c|}{ Roadway versus off-road* } \\
\hline & $\overline{\mathrm{OR}}(95 \% \mathrm{CI})$ & aOR $(95 \% \mathrm{CI})^{*}$ \\
\hline \multicolumn{3}{|l|}{ Rider characteristics } \\
\hline \multicolumn{3}{|l|}{ Sex } \\
\hline Male & $1.07(0.93$ to 1.23$)$ & $0.95(0.81$ to 1.12$)$ \\
\hline Female & 1.0 (ref) & 1.0 (ref) \\
\hline \multicolumn{3}{|l|}{ Age } \\
\hline$<16$ & $0.74(0.67$ to 0.81$)$ & $0.74(0.65$ to 0.85$)$ \\
\hline$\geq 16$ & 1.0 (ref) & 1.0 (ref) \\
\hline \multicolumn{3}{|l|}{ Seating position } \\
\hline Operator alone & 1.0 (ref) & 1.0 (ref) \\
\hline Operator w/passenger & 1.38 (1.21 to 1.58$)$ & $1.19(1.02$ to 1.38$)$ \\
\hline Passenger & $1.35(1.18$ to 1.56$)$ & $1.48(1.23$ to 1.77$)$ \\
\hline \multicolumn{3}{|l|}{ Helmet } \\
\hline Yes & $0.68(0.62$ to 0.75$)$ & $0.56(0.49$ to 0.65$)$ \\
\hline No & 1.0 (ref) & 1.0 (ref) \\
\hline \multicolumn{3}{|l|}{ Alcohol } \\
\hline Yes & $1.96(1.74$ to 2.21$)$ & $1.77(1.53$ to 2.05$)$ \\
\hline No & 1.0 (ref) & 1.0 (ref) \\
\hline \multicolumn{3}{|l|}{ Drugs } \\
\hline Yes-medication & $0.70(0.46$ to 1.06$)$ & $0.78(0.49$ to 1.22$)$ \\
\hline Yes-illicit & $1.73(1.33$ to 2.25$)$ & $1.17(0.87$ to 1.57$)$ \\
\hline No & 1.0 (ref) & 1.0 (ref) \\
\hline \multicolumn{3}{|l|}{ Mechanism of crash } \\
\hline ATV-vehicle collision & $10.4(8.9$ to 12.2$)$ & 11.1 (9.24 to 13.32$)$ \\
\hline ATV-other collision & 3.5 (3.19 to 3.90$)$ & 3.74 (3.31 to 4.22$)$ \\
\hline Non-collision & 1.0 (ref) & 1.0 (ref) \\
\hline
\end{tabular}

ATV, All-terrain vehicle.

${ }^{*}$ Adjusted odds ratios (aOR) were controlled for all other covariables in the table. an increase in compression asphyxia cases over time that is consistent with this hypothesis.

\section{Multiple victims}

Results indicate that fatal roadway crashes were three times more likely to involve multiple victims than off-road crashes. This may reflect, in part, the higher proportion of crashes with multiple riders. Most ATVs are designed for a single rider only, and have visible warning labels against passenger use. Despite this, carrying passengers has been shown to be a widespread practice. $^{1419}$ Epidemiological studies demonstrate that passengers are an independent risk factor for injury. ${ }^{20}$ Passengers can prevent proper 'active riding' by the operator, alter the centre of gravity, and be a distraction, all of which increase the likelihood of certain crash mechanisms (eg, rollovers and collisions).

The higher proportion of multiple fatalities in roadway crashes may also be related to the higher likelihood of vehiclevehicle collisions. Colliding with larger vehicles on the road may result in higher crash forces that consequently increase the likelihood of fatality. Considering the fact that ATVs are less likely to be driven in high-traffic environments, that is, more likely in rural communities, the preponderance of collisions is striking. The higher likelihood of multiple fatalities on the roadway illustrates the importance of having and enforcing 'no-passenger laws', and the critical need to get ATVs off the road to protect both ATV users and other motorists.

\section{Alcohol use among adult victims}

Previous studies suggest that alcohol contributes to $40-50 \%$ of fatal ATV crashes. ${ }^{21} 22$ We found that $39 \%$ of adult fatalities (victims over 16 years of age) involved alcohol use, and that alcohol was more likely to be involved on the roadway than off. This may reflect the higher proportion of younger adults (16-25 years of age) who were involved in fatal roadway crashes, as this age range has been shown to be more likely to use alcohol and drive. ${ }^{23}$ Moreover, ATVs are more common in rural and suburban communities, and rural youth and young adults are more likely to use alcohol than their urban peers. ${ }^{24}$ It is illegal in some, but not all, states to drink and operate an 
Table 4 Unadjusted and adjusted odds of ATV fatalities comparing helmet versus no helmet and with head injury versus no head injury; CPSC, 1995-2009, ( $\mathrm{n}=9615$ fatalities)

\begin{tabular}{|c|c|c|c|c|}
\hline & \multicolumn{2}{|l|}{ Helmet use* } & \multicolumn{2}{|l|}{ Head injuryt } \\
\hline & $\overline{\mathrm{OR}}(\mathbf{9 5 \%} \mathrm{CI})$ & aOR $(95 \% \mathrm{Cl})$ & $\overline{\mathrm{OR}}(95 \% \mathrm{CI})$ & aOR $(95 \% \mathrm{Cl})$ \\
\hline \multicolumn{5}{|l|}{ Rider characteristics } \\
\hline \multicolumn{5}{|l|}{ Sex } \\
\hline Female & 1.0 (ref) & 1.0 (ref) & 1.0 (ref) & 1.0 (ref) \\
\hline \multicolumn{5}{|l|}{ Age } \\
\hline$<16$ & 1.79 (1.57 to 2.05$)$ & 1.76 (1.51 to 2.07$)$ & $1.21(1.10$ to 1.33$)$ & 1.28 (1.12 to 1.45$)$ \\
\hline Operator alone & 1.0 (ref) & 1.0 (ref) & 1.0 (ref) & 1.0 (ref) \\
\hline Operator w/passenger & $0.44(0.36$ to 0.55$)$ & 0.41 (0.33 to 0.51$)$ & $1.27(1.11$ to 1.45$)$ & $1.04(0.90$ to 1.20$)$ \\
\hline Passenger & $0.52(0.41$ to 0.65$)$ & 0.42 (0.33 to 0.54$)$ & $1.66(1.44$ to 1.92$)$ & 1.41 (1.19 to 1.67$)$ \\
\hline \multicolumn{5}{|l|}{ Helmet } \\
\hline Yes & NA & & 0.52 (0.46 to 0.59 ) & 0.54 (0.47 to 0.62$)$ \\
\hline \multicolumn{5}{|l|}{ Alcohol } \\
\hline \multicolumn{5}{|l|}{ Drugs } \\
\hline Yes-medication & $0.47(0.24$ to 0.90$)$ & 0.47 (0.24 to 0.94$)$ & 0.60 (0.40 to 0.91$)$ & 0.65 (0.41 to 1.01$)$ \\
\hline Yes-illicit & $0.66(0.47$ to 0.93$)$ & 0.99 (0.68 to 1.42 ) & $1.28(0.99$ to 1.65$)$ & 1.19 (0.91 to 1.56$)$ \\
\hline No & 1.0 (ref) & 1.0 (ref) & 1.0 (ref) & 1.0 (ref) \\
\hline \multicolumn{5}{|l|}{ Helmeted victim } \\
\hline On-road & NA & & $1.46(1.13$ to 1.88$)$ & $1.33(1.00$ to 1.76$)$ \\
\hline Off-road & & & 1.0 (ref) & 1.0 (ref) \\
\hline \multicolumn{5}{|l|}{ Mechanism of crash } \\
\hline ATV-vehicle collision & NA & & 1.62 (1.44 to 1.82$)$ & 1.08 (0.93 to 1.27$)$ \\
\hline ATV-other collision & & & 1.35 (1.22 to 1.49$)$ & 1.01 (0.89 to 1.15$)$ \\
\hline Non-collision & & & 1.0 (ref) & 1.0 (ref) \\
\hline \multicolumn{5}{|l|}{ Location } \\
\hline
\end{tabular}

${ }^{*}$ Referent is not using a helmet.

tReferent is without head injury.

ATV, All-terrain vehicle; NA, not applicable.

ATV. However, attitudes that ATVs are large toys may prevent riders from appreciating the risk of drinking and driving, even if they appreciate it for other motor vehicles.

\section{Helmet use and head injuries}

Studies including ours have documented low helmet use among ATV riders in non-fatal crashes, ${ }^{21} 25$ with paediatric use ranging from $16 \%$ to $28 \%{ }^{7}{ }^{26}$ We found similar helmet use among Iowa youth ( 25\%). ${ }^{17}$ Previous studies have also found that helmet use was even lower in fatal crashes $(5-15 \%),{ }^{27}$ again similar to the present results. Passenger helmet use has previously been reported to be lower than operator use in nonfatal crashes, ${ }^{17} 28$ and we found this was true for fatal crashes as well. Our fatality analysis further demonstrates that helmet use was lower on the roadway than off, among adults as compared with youth, when vehicles had multiple riders, and when alcohol was involved. Taken together, these results suggest that lack of helmet use is associated with a higher likelihood of other risky behaviours.

Brain injury is among the leading causes of fatality and disability from ATV crashes. 72930 We recently reported that nonfatal roadway crashes had a higher likelihood of head injury as compared with off-road crashes; ${ }^{17}$ and our data show that this is also true for roadway crashes that are fatal. Although younger victims were more likely to be helmeted than adults, their likelihood of head injury was higher, even when controlling for other variables. This is likely due to several factors including a potentially lower tolerance to force for youth helmets, improper fit, and/or a greater vulnerability of a younger brain. Head injuries were also more likely among passengers. Passengers restrict operator movement and may reduce the operator's/passenger's ability to self-eject and use their extremities to avoid or decrease head impact. Passengers are also more likely to be ejected to the rear where they are less able to protect their head.

It was previously estimated that helmets reduce the risk of fatal ATV-related head injuries by $42 \%{ }^{12} 2831$ We found a $46 \%$ decrease in the likelihood of a head injury among helmeted fatality victims. It should be noted, however, that helmeted roadway riders were more likely to suffer a head injury than helmeted riders off-road. We hypothesise that this is due, in part, to higher speeds on the road that result in higher energy transfers exceeding the protective limits of the helmet, or that create rotational effects on the brain that may not be protected by helmet use.

\section{Prevention strategies}

The high proportion of roadway fatalities is disturbing, as many states strictly limit ATV road use. A similar lack of compliance with other ATV laws and limited reductions in injuries following passage of laws by some states have led several investigators to question their effectiveness. ${ }^{32-34}$ However, other investigators have reported associations between passage of 
ATV laws and decreased fatality rates. ${ }^{35}{ }^{36}$ Most recently, Helmkamp et $a l^{37}$ found that ATV helmet laws reduced fatality rates, but training requirements appeared to have no effect. In addition, studies questioning the effectiveness of ATV laws did not fully consider user knowledge and enforcement challenges. The former may be low, ${ }^{38}$ and the latter includes catching off-road riders and lack of jurisdiction on private property. Research on seat belt and child safety seat laws indicates that increasing compliance requires extensive user education/training and effective enforcement strategies. ${ }^{39}$ The most effective programmes, like the Click It or Ticket programme in Utah, involve an integration between the two. ${ }^{40}$

\section{Study limitations}

Although documentation varied, only three of 21 variables had documentation levels below 60\% (engine size, 56\%; alcohol, $53 \%$; drugs, $37 \%$ ). In addition to low documentation of alcohol use, it is currently unknown how many victims were tested. Incomplete documentation could impact some of our conclusions, but the large number of fatalities in the study reduces this likelihood. The accuracy of the roadway/off-road coding was difficult to judge, as no narrative is collected and other crash details were highly limited. There were also limitations on our ability to identify the fatal injury, as the cause of fatality narrative was often general. For this reason, we chose to look at total injuries by combining data from several CPSC fields. The non-specific nature of the cause of fatality narratives, and the recording of only one injured body part per crash victim, however, may underestimate these totals. While we cannot rule out the possibility that undercounting differentially affected variables, for example, roadway versus off-road crashes, this seems highly unlikely for a large dataset. Thus, we would argue that our proportional comparisons are likely to be valid.

\section{CONCLUSIONS}

CPSC data indicate that over $60 \%$ of ATV-related fatalities result from roadway crashes. This is probably due to a complex interplay between the increased risk of losing control at roadway speeds and/or of colliding with another vehicle, as well as the increased practice of carrying passengers, using alcohol, and not wearing a helmet. In addition, roadway fatalities have been increasing at a higher rate than off-road fatalities, possibly due to the rising popularity of larger, faster machines. Preventing ATV-related fatalities will require substantially more investment in rider education, as well as the passage and effective enforcement of laws restricting ATV road use in every state. States should also invest more in passing and enforcing helmet laws and laws prohibiting alcohol use. The high human and financial burden of these fatalities would justify such an investment as an important contributor to improved public health and safety.

\section{What is already known on this subject}

- ATV-related fatalities and injuries are a significant health and safety issue in rural communities.

- Children and young adults, 25 years of age and younger, represent over half of all ATV crash victims.

- West Virginia is the only state that has reported the percentage of fatal ATV crashes that occurred on the roads, $60 \%$ from 1999-2004.

\section{What this study adds}

Nationwide, from 1985 through 2009, 62\% of fatal ATV crashes occurred on the road, and starting in 1998, fatal on-road crashes increased at over twice the rate of off-road crashes.

- Relative to off-road crashes, fatal on-road crashes were more likely to involve victims $16-25$ years of age, multiple victims, carrying passengers, collisions and alcohol use.

- On-road riders were less likely to be helmeted, and helmet use was associated with a $46 \%$ decrease in the likelihood of a head injury.

Acknowledgements We would like to thank the Consumer Product Safety Commission for providing us with these data, and our collaborators in the lowa Injury Prevention Research Center for their insights and support.

Contributors GMD requested access of the CPSC data, created the ACCESS database, provided supervision to the student research assistant DGE, and was involved in data analysis and preparation of the manuscript. KKH was primarily responsible for statistical analysis and helped in the preparation of the manuscript. DGE was primarily responsible for organising and compiling the data in the ACCESS database and for generating preliminary frequency data. CAJ shared overall responsibility with GMD in the design of the study questions, in interpretation of study results, and in final preparation of the manuscript.

Funding The University of lowa Department of Emergency Medicine provided funding for these studies.

\section{Competing interests None.}

Provenance and peer review Not commissioned; externally peer reviewed.

Data sharing statement The CPSC provided us with their data through an online request form. The link to that form is provided in the text. In addition, we would be happy, with the permission of the CPSC, to share the data for collaboration purposes.

Open Access This is an Open Access article distributed in accordance with the Creative Commons Attribution Non Commercial (CC BY-NC 3.0) license, which permits others to distribute, remix, adapt, build upon this work non-commercially, and license their derivative works on different terms, provided the original work is properly cited and the use is non-commercial. See: http://creativecommons.org/icenses/by-nc/3.0/

\section{REFERENCES}

1. Consumer Product Safety Commission. 2010 Annual Report of ATV-Related Deaths and Injuries. 2011. http://www.cpsc.gov/library/foia/foia12/os/atv2010.pdf (accessed 11 Apr 2012).

2. Consumer Federation of America. All-Terrain Vehicle (ATV) Safety Crisis: America's Children at Risk. 2007. http://www.consumerfed.org/pdfs/ATV_Fact_ Sheet_07_final.pdf

3. Consumer Product Safety Commission. 2009 Annual Report of ATV-Related Deaths and Injuries. 2010. http://www.consumerfed.org/news-room/studies \#2003 (accessed 6 Dec 2012).

4. Fisher RM, Berg RL, Marlenga B. Children's exposures to farm worksite hazards on management-intensive grazing operations. J Agromedicine 2009;14:192-7.

5. Hendricks KJ, Myers JR, Layne LA, et al. Household youth on minority operated farms in the United States, 2000: exposures to and injuries from work, horses, ATVs and tractors. J Safety Res 2005;36:149-57.

6. Aitken ME, Graham CJ, Killingsworth JB, et al. All-terrain vehicle injury in children: strategies for prevention. Inj Prev 2004;10:303-7.

7. Gittelman MA, Pomerantz WJ, Groner Jl, et al. Pediatric all-terrain vehicle-related injuries in Ohio from 1995 to 2001: using the injury severity score to determine whether helmets are a solution. Pediatrics 2006;117:2190-5.

8. Rodgers GB. Factors associated with the all-terrain vehicle mortality rate in the United States: an analysis of state-level data. Accid Anal Prev 2008;40:725-32.

9. Shulruf B, Balemi A. Risk and preventive factors for fatalities in all-terrain vehicle accidents in New Zealand. Accid Anal Prev 2010;42:612-18.

10. General Accounting Office (GAO). All-terrain vehicles: How they are used, crashes, and sales of adult-sized vehicles for children's use. Report to Congressional Committees (GAO-10-418). 2010. http://www.gao.gov/new.items/d10418.pdf (accessed 20 Jan 2012).

11. Helmkamp JC. ATV-related deaths in West Virginia: 1990-2003. W V Med J 2003;99:224-7. 
12. Rodgers GB. The effectiveness of helmets in reducing all-terrain vehicle injuries and deaths. Accid Anal Prev 1990;22:47-58.

13. Krueger D. Investigation of Lateral Performance of an ATV Tire on Natural, Deformable Surfaces. Master of Science Thesis, Auburn University, 2007. (accessed 26 0ct 2012).

14. Hafner JW, Hough SM, Getz MA, et al. All-terrain vehicle safety and use patterns in central Illinois youth. J Rural Health 2010;26:67-72.

15. Helmkamp JC, Ramsey WD, Haas SM, et al. All-terrain vehicle (ATV) deaths and injuries in West Virginia: A summary of surveillance and data sources. Charleston, WV: Criminal Justice Statistical Analysis center, Division of Criminal Justices Services, Department of Military Affairs and Public Safety. 2008. http://www.wvdcjs.com/ statanalysis (accessed 21 Nov 2011)

16. CPSC Clearinghouse. Request for data form. http://www.cpsc.gov/cgibin/ clearinghouse.aspx (accessed 25 Jun 2012).

17. Denning GM, Jennissen CA, Harland $\mathrm{K}$, et al. All-terrain vehicles (ATVs) on the road: a serious traffic safety and public health concern traffic. Traffic Inj Prev 2012;14:1-8.

18. Murphy N, Yanchar NL. Yet more pediatric injuries associated with all-terrain vehicles: should kids be using them? J Trauma 2004;56:1185-90.

19. Campbell BT, Kelliher KM, Borrup K, et al. All-terrain vehicle riding among youth: how do they fair? J Pediatr Surg 2010;45:925-9.

20. Rodgers GB, Adler P. Risk factors for all-terrain vehicle injuries: a national case-control study. Am J Epidemiol 2001;153:1112-18.

21. Fonseca $\mathbf{A H}, 0$ chsner MG, Bromberg WJ, et al. All-terrain vehicle injuries: are they dangerous? A 6-year experience at a level I trauma center after legislative regulations expired. Am Surg 2005;71:937-40; discussion 940-1.

22. Carr AM, Bailes JE, Helmkamp JC, et al. Neurological injury and death in all-terrain vehicle crashes in West Virginia: a 10-year retrospective review. Neurosurgery 2004;54:861-6; discussion 866-7.

23. Adams BD, Medeiros R, Dereska P, et al. Geriatric all-terrain vehicle trauma. Am Surg 2004;70:329-32.

24. Coomber K, Toumbourou JW, Miller P, et al. Rural adolescent alcohol, tobacco, and illicit drug use: a comparison of students in Victoria, Australia, and Washington State, United States. J Rural Health 2011:27:409-15.

25. Brandenburg MA, Archer $P$, Mallonee $S$. All-terrain vehicle-related central nervous system injuries in Oklahoma. J Okla State Med Assoc 2005:98:194-9.
26. Wang BS, Smith SL, Pereira KD. Pediatric head and neck trauma from all-terrain vehicle accidents. Otolaryngol Head Neck Surg 2007;137:201-5.

27. Helmkamp JC. Adolescent all-terrain vehicle deaths in West Virginia, 1990-1998. W V Med J 2000;96:361-3.

28. Merrigan TL, Wall PL, Smith HL, et al. The burden of unhelmeted and uninsured ATV drivers and passengers. Traffic Inj Prev 2011;12:251-5.

29. Bowman SM, Aitken ME, Helmkamp JC, et al. Impact of helmets on injuries to riders of all-terrain vehicles. Inj Prev 2009;15:3-7.

30. Brandenburg MA, Brown SJ, Archer P, et al. All-terrain vehicle crash factors and associated injuries in patients presenting to a regional trauma center. J Trauma 2007;63:994-9

31. Myers ML, Cole HP, Mazur JM. Cost effectiveness of wearing head protection on all-terrain vehicles. J Agromedicine 2009;14:312-23.

32. Beidler SK, Kromhout-Schiro S, Douillet CD, et al. North Carolina all-terrain vehicle (ATV) safety legislation: an assessment of the short-term impact on ATV-related morbidity and mortality. N C Med J 2009;70:503-6.

33. McBride AS, Cline DM, Neiberg RH, et al. Pediatric all-terrain vehicle injuries: does legislation make a dent? Pediatr Emerg Care 2011;27:97-101.

34. Winfield RD, Mozingo DW, Armstrong JH, et al. All-terrain vehicle safety in Florida: is legislation really the answer? Am Surg 2010;76:149-53.

35. Cain L, Helmkamp J. Geographic and temporal comparisons of ATV deaths in West Virginia 2000-2008. W V Med J 2010;106:26-9.

36. Upperman JS, Shultz B, Gaines BA, et al. All-terrain vehicle rules and regulations: impact on pediatric mortality. J Pediatr Surg 2003;38:1284-6.

37. Helmkamp JC, Aitken ME, Graham J, et al. State-specific ATV-related fatality rates: an update in the new millennium. Public Health Rep 2012;127: 364-74.

38. Jennissen CA, Denning GM, Sweat $S$, et al. All-terrain vehicle injury prevention: healthcare providers' knowledge, attitudes, and the anticipatory guidance they provide. J Community Health 2012;37:968-75.

39. St Mars T. 2006 ENA National Scorecard on State Highway Laws: a road map for injury prevention. J Emerg Nurs 2007;33:265-70.

40. Thomas AM, Cook LJ, Olson LM. Evaluation of the Click It or Ticket intervention in Utah. Accid Anal Prev 2011:43:272-5.

\section{Some states to defy congressional gun regulations}

In mid-April, Kansas passed a law asserting that federal gun regulations do not apply to firearms made and owned in Kansas. Under the law, Kansans could manufacture and sell semiautomatic weapons within the state without a federal license or any federal oversight. Similar bills have been introduced in 37 other states. An even broader bill, would exempt any gun owned by an Alaskan from US regulation. Many observers see these so-called nullification bills as 'political theatre' and say they are likely to be struck down in the courts (ProPublica).

\section{Small SUVs do poorly on new test simulating deadly collisions}

The small-overlap crash test models collisions occurring when a vehicle hits a hard barrier with just a quarter of its bumper, concentrates force in a small area unprotected by strong safety structures built into most new vehicles. Such crashes cause $25 \%$ of serious injuries or deaths in frontal collisions, but many small SUVs fared poorly in a recent round of testing by the Insurance Institute for Highway Safety. Only the 2013 Subaru Forrester and 2014 Mitsubishi Outlander Sport performed well, while five SUVs were rated 'poor', with the worst marks going to the Ford Escape. Most of the SUVs tested, however, have performed well on other types of safety tests (CBS News, WETM (Corning, NY)). 